\section{Organizational culture and cultural diversity: an explorative study of international skilled migrants in Swedish firms}

International skilled migrants

\author{
Ali Farashah \\ School of Business, Society and Engineering, Mälardalen University, \\ Västerås, Sweden, and \\ Tomas Blomqusit \\ Umeå School of Business, Economics and Statistics, Umeå University, Umeå, Sweden
}

Received 5 November 2020 Revised 26 February 2021 Accepted 26 February 2021

\begin{abstract}
Purpose - This paper empirically explores the types and extent of cultural diversity strategies in Sweden, a developed economy with many migrant workers. The role of organizational culture as the context and the association with diversity strategy and the selection of international skilled migrant workers are examined.

Design/methodology/approach - Empirical data are collected by surveying 249 Swedish large or mediumsized firms. Cluster analysis is used to explore the configuration of organizational culture, cultural diversity strategy (CDS) and selection and development criteria.

Findings - The authors identify five clusters of organizations. Organizational culture is the main contextual factor that influences the CDS and human resource (HR) approaches for selecting skilled migrant workers. The profile of the clusters including organizational culture, diversity strategies, the selection criteria and firm demographics is presented. The empirical results indicate that organizational culture and demographics are associated with the choice of diversity strategy and, consequently, HR processes.

Originality/value - This study's main focus is on international skilled migrants, which is among empirically less-studied areas in global mobility literature. Furthermore, until now more attention has been directed toward studying the consequences of diversity than toward understanding the factors that influence choice of diversity strategies and practices. This study focuses on antecedents of diversity and attempts to understand the factors that influence adoption and implementation of different cultural diversity strategies.
\end{abstract}

Keywords Cultural diversity, Skilled migrant, Migrant workers, Organizational culture, Selection, Promotion, Sweden, Clustering

Paper type Research paper

\section{Introduction}

The number of people who immigrate to live and work permanently in another country is increasing. In addition, diversity based on national origin in the labor market is increasing, and migrant workers now constitute around $5 \%$ of the global labor force (OECD, 2019). The European Union and North America are among the leading destinations for migrant workers due to their economic prosperity and better life and employment opportunities. On the other hand, the host countries benefit from an increased supply of talent and workforce in sectors with labor shortages.

(C) Ali Farashah and Tomas Blomqusit. Published by Emerald Publishing Limited. This article is published under the Creative Commons Attribution (CC BY 4.0) licence. Anyone may reproduce, distribute, translate and create derivative works of this article (for both commercial and non-commercial purposes), subject to full attribution to the original publication and authors. The full terms of this licence

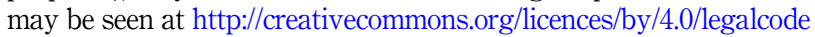

This research was supported by Swedish Research Council for Health, Working life and Welfare (FORTE) under grant Dnr: 2017-00285.

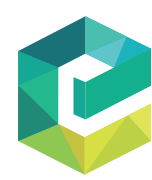

Journal of Global Mobility: The Home of Expatriate Management Research Vol. 9 No. 2, 202 pp. $289-308$ Emerald Publishing Limited
$2049-8799$ DOI 10.1108/JGM-11-2020-0072 
JGM

9,2

290
Migrant workers are a diverse group and include various forms of global work and international work experience (Andresen et al., 2014). International skilled migrants (ISMs) are the main focus in this research. ISMs are a group different than self-initiated expatriates (SIEs) and corporate expatriates (CEs). The primary focus of ISMs is movement across national borders rather than organizational boundaries, which is the case for SIEs and CEs. ISMs' main motivation for migration is settlement in the new country, and they intent to stay for an indefinite period of time (sometimes permanently), while CEs and SIEs have no intention to settle (Hajro et al., 2019). ISMs, unlike expatriates, do not have a sponsor and are not employed at the time of arrival (Selmer, 1999). Following the study of Hajro et al. (2017) and Cerdin et al. (2014), we define ISMs as migrants with at least a bachelor's degree or equivalent who have moved legally to work and live abroad for an indefinite period of time. This group, however, is diverse and may include people who migrate to reunite their family, refugees, students or expatriates who after finishing studies or the assignment decide to stay as they have developed a personal and professional network in the new country.

Diversity management is a managerial tool to ensure representation of minorities of all kinds including ISM. We investigate cultural diversity management referring to deliberate organizational actions that aim at promoting equal opportunity, equal treatment and greater inclusion of employees in regards to their national origin and ethnicity. Organizations have different perspectives on diversity management. Some of the approaches are as follows: moral and ethical reasoning, which consider diversity management an antidiscriminatory act and the right thing to do; the business case, which assumes the strategic value of diversity and its positive effect on innovation and performance; and the imperative view, which postulates that diversity management is necessary to cope with the reality of increased diversity in a globalized economy (Barak, 2016). However, there is limited empirical research into the prevalence of these diversity strategies. An important area for future investigation is to examine differences in diversity management and the extent of these practices (Yang and Konrad, 2011). In particular, cultural diversity management, a subset of diversity management, has not been extensively studied. Therefore, we explore the main strategies for cultural diversity and the extent of adoption and practice of these strategies.

More attention has been directed toward studying the outcomes of diversity than toward understanding the factors that influence adoption and implementation of diversity. In particular, in examining cultural diversity, little research has explored the effect of organizational context. Organizational culture is considered in this study because it is one of the most central contextual factors. Organizational culture, as a set of shared values and perceptions, influences all aspects of the organization, including structure, strategy, leadership and processes (Hartnell et al., 2019). Therefore, to shed light on the antecedents of diversity, the connection between organizational culture and cultural diversity strategy (CDS) is explored.

In order to evaluate consequences of diversity strategies, the selection and development functions of HR are examined. Research shows that ISM workers are frequently employed in jobs that do not match their level of skill and education and have lower levels of pay, status and job security (e.g. Emilsson and Irastorza, 2019; Janssens and Zanoni, 2014; Leschke and Weiss, 2020; McGuire and Lozada, 2017; Ressia et al., 2017; Wassermann et al., 2017). Differences in employment rate and career attainment of migrant workers might be partially explained by differences in human capital, demographics, lower levels of language proficiency and the time required for work role transition and adjustment to new norms or job content (Cooke et al., 2013; Rodriguez et al., 2012; Supangco and Mayrhofer, 2014). However, discrimination is considered a complementary explaining factor (Guerrero and Hakak, 2019; Luik et al., 2018; Murray and Ali, 2017). Equality in recruitment and promotion processes can significantly improve career outcomes of migrants. Therefore, the relationship between CDS and the selection and career development of ISMs is explored. The requirements that organizational decision-makers use for employment and career advancement decisions affect migrant workers' career attainment, 
often negatively and sometimes positively (Fernando and Cohen, 2016; Wittek, 2019). Therefore, it is essential to compare different diversity strategies in terms of their focal criteria for employment and career advancement.

To develop a universal understanding of diversity, more studies are required pertaining to contexts other than the United States, mainly due to the differing legislative, social and historical contexts in which diversity can occur in different countries (Shore et al., 2018). This study examines diversity strategies in Swedish organizations. Sweden has hosted a proportionally large number of migrants in recent decades. Despite increased cultural diversity among workers, the challenge of a higher unemployment rate among foreign-born individuals persists (e.g. 9.3\% foreign-born vs $2.7 \%$ Swedish-born individuals with a university degree are unemployed) (Statistics Sweden, 2019).

Through empirical and explorative inquiry, this study attempts to better understand the complexity of diversity in organizations. The main cultural diversity approaches are identified, and their association with organizational culture, selection criteria and firm demographics is revealed.

The remainder of this paper is structured as follows. First, a summary of the previous research and a typology of CDSs, organizational culture and selection and promotion criteria are presented. Then the study's method and respondent organizations are introduced. Using mean comparison tests, the most common CDSs are identified. Also, using classification clustering, the relationship between organizational culture and diversity strategies is revealed. The results, their contribution to the diversity and global mobility field and directions for future research are discussed at the end of the paper.

\section{Cultural diversity strategies}

Several organizational diversity strategies (also referred to as a diversity approach, diversity orientation and diversity perspective) have been identified in the previous research. Among the studies with the most comprehensive lists of CDSs, Podsiadlowski et al. (2013) and Ortlieb and Sieben (2013) each identified five strategies addressing diversity. Juxtaposing these two studies results in the identification of six independent types of CDS at the organizational level:

(1) Homogeneity strategy. In line with the similarity-attraction effect (Montoya and Horton, 2013), this strategy emphasizes person-organization fit and seeks employees with values, attitudes and behaviors similar to the majority within the organization. Organizations adopting this strategy underline the importance of local culture and norms to reach a higher level of homogeneity, communication and customer satisfaction and to avoid conflict and delay in decision-making processes.

(2) Blind strategy. This strategy focuses on the person-job fit to select and retain the best-qualified employees, irrespective of their cultural background. As long as the candidate meets the technical job qualifications, he/she is considered employable.

(3) Fairness strategy. Like the blind strategy, the fairness strategy is antidiscriminatory and focuses not only on providing equal opportunities but also provides support to employees with different cultural backgrounds for their employment and development. For example, the organization might set a quota for employing migrant workers. Organizations with this strategy believe that the demographics of society should be reflected in the organization.

(4) Learning strategy. This strategy emphasizes the new and distinctive perspectives, skills and knowledge that workers from a different culture transfer. This new perspective is considered an essential source of innovation and learning at the team and organizational levels. 
JGM

9,2

292

(5) Access strategy. This strategy is primarily characterized by the inclusion of culturally diverse employees in order to reach and serve a diverse clientele. In this strategy, migrants are often employed as cultural brokers. Due to their familiarity with both the host and home cultures, migrants can help the organization operate in new markets or provide a higher level of customer service to culturally diverse customers.

(6) Good worker strategy refers to a strategy that the employer is inclined to utilize migrant workers, which are often marginalized and have a vulnerable position in the labor market. This strategy aims to get the most out of migrant workers. Since migrants have lower negotiation power, they are more flexible and therefore attractive for certain employers (MacKenzie and Forde, 2009). For them, migrant workers are perceived as good workers with strong work ethics, more flexibility and less demands (MacKenzie and Forde, 2009; Ortlieb and Sieben, 2013). Good worker strategy is related to the occupations with shortage of skills but the shortage is often after domestic workers are unwilling to take the jobs with unfavorable conditions. In such cases, good (migrant) workers willingly take the job and for example work longer and in more flexible hours (Thompson et al., 2013). Pursuing this strategy often leads migrant workers to be employed in overqualified positions and fill less desirable positions with lower wages or flawed career perspectives (Janssens and Zanoni, 2005).

Taking into account this typology, we attempt to identify the extent of utilization of each strategy in the Swedish context. Furthermore, we explore the effect of organizational culture on the choice of CDS and the effects of CDS on selection and promotion of IMSs.

\section{Organizational culture and CDS}

Organizational culture is defined as "shared values and basic assumptions that explain why organizations do what they do and focus on what they focus on" (Schneider et al., 2017). Based on two organizational dimensions of focus (on the internal environment and integration vs external environment and differentiation) and structure (value stability and control vs accentuating flexibility and discretion), Cameron and Quinn (1999) suggested four types of organizational culture, as shown in Figure 1. The clan culture emphasizes cohesion, collaboration and commitment in the form of teamwork, participation and consensus. It encourages members to embrace organizational goals and values. Within such a culture, the organization is like a family or tribe, and communication, knowledge-sharing, loyalty and relationship with employees, customers and suppliers are valued. The ad hocracy culture is characterized by entrepreneurship and innovation. Within such a culture, exploiting opportunities, ingenious problem-solving and risk-taking are valued, and employees have higher levels of discretion to break routines, be creative and exploit opportunities. The market culture reflects a rational and competitive entity, is result-oriented, emphasizes control, has clear objectives and rewards individual accomplishment and performance (Balaji et al., 2020). The hierarchy culture is associated with formal rules and routines to which employees are required to conform. A centralized and strict control system attempts to ensure efficiency and predictability in such an organization. One culture is not necessarily more productive than others, and the choice of culture depends on the organization's industry and strategy and is based on founders' values and historical events during organizational growth.

National and international regulations and legislation create coercive pressure to force organizations to adopt diversity management. However, Dobbin et al. (2011) showed that for legitimacy-enhancing innovations such as diversity management, adoption is primarily driven by organizational culture not by need or institutional pressure. Organizational culture can influence how an organization relates to the diversity characteristics of its employees and shapes the perceived experiences of employees with those characteristics (Findler et al., 2007; 


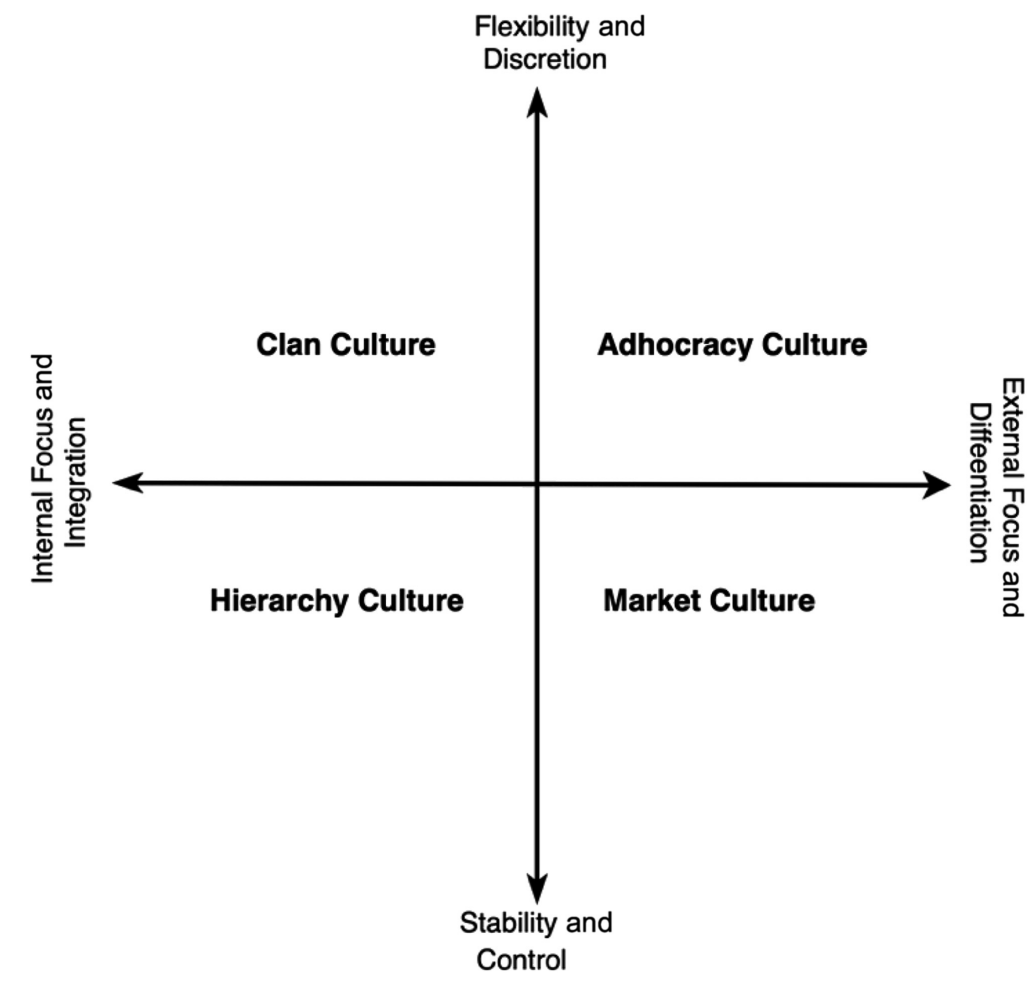

International skilled migrants

Figure 1 .

Organizational culture typology based on Cameron and Quinn (1999)

Shore et al., 2018). Several studies suggest that certain types of organizational culture assist or obstruct particular diversity management practices, and that organizational culture significantly influences the outcomes and results of firm diversity (e.g. Dwyer et al., 2003; Guillaume et al., 2017; Holvino and Kamp, 2009).

Therefore, the first research question is as follows:

$R Q 1$. What is the relationship between organizational culture and CDS? Are there patterns of association between the organizational culture and the choice of CDS?

Furthermore, organizational demographics such as size, degree of internationalization, working language and the general educational level of employed migrant workers were considered contextual factors that might be associated with the CDS.

\section{Selection/development and CDS}

Regarding the consequences of CDSs, we focus on HR, and particularly the selection and development (i.e. promotion) process. Empirical evidence indicates the importance of migrant status on employment and career outcomes. Although the effect of human capital (i.e. formal education) on migrants' employment and career attainment has been shown to be positive, especially if the education and work experience is obtained locally (Nordin and Rooth, 2007), differences in human capital do not entirely explain the employment differential between native and migrant workers. Researchers have noted the roles of different factors in the selection of migrants, including local language (e.g. Cooke et al., 2013; Guerrero and Rothstein, 
JGM

9,2

294
2012), social capital (e.g. Sarpong and Maclean, 2019; Shirmohammadi et al., 2019) and cultural capital, referring to the local vocational norms, behaviors and unwritten laws of work culture and host countries' value systems (e.g. Al Ariss and Syed, 2011; Hakak et al., 2010; Lu et al., 2016). The essence of most selection systems is comparing shortlisted candidates based on a set of criteria. Often, more than one candidate is assessed as appointable, and when none of the candidates exceeds the others by a great margin, the selection decision tends to be based on how acceptable the candidate seems to be, particularly with respect to the workplace or national culture (Farashah and Blomquist, 2020; Noon, 2012). This criterion relates to the concept of cultural capital (referring to the notion of embodied cultural capital in Bourdieu's theory of practice (2008)) that is widely used in migration studies (Erel, 2010).

Another school of HR uses competency models as the foundation for selection, appraisal, and development of employees. Competency-based HR focuses on individuals' behavioral characteristics that relate to quality performance instead of characteristics such as human capital. Because competency-based HR is devoted to tangible performance, it is considered an effective way to address the challenge of diversity.

Therefore, expanding the career capital theory (DeFillippi and Arthur, 1994) and Bourdieu's notion of cultural capital (Bourdieu, 2008) in the context of migrant worker selection (Cooke et al., 2013; Joy et al., 2018), the following five types of selection and appraisal criteria for immigrant workers are identified and included in this study: (1) human capital, (2) language proficiency, (3) cultural capital, (4) social capital and (5) competencies. Similar to previous question, the second research question is as follows:

RQ2. What is the relationship between CDS and selection and development processes?

\section{Method}

Our study explores how various organizational cultures contribute to cultural diversity by means of diversity strategy and selection of ISMs. Because of the absence of prior theory and research on the relationship of culture and diversity, an explorative approach was adopted.

\section{Sample}

Empirical data were gathered by surveying Swedish large and medium-sized businesses. Through the survey, data about the demographics of the business, the organizational culture, approach to cultural diversity and criteria for selecting an IMS were gathered. To ensure directing the respondents to focus on cultural diversity and case of ISMs, the invitation email containing the survey link and the introduction page of the survey included the definition of ISMs as migrants with a university degree from another country and not with the employer sponsored residency visa at the time of arrival. In particular, the commonly used term in Swedish media referring to our target (i.e. "akademiker" for university graduate and "nyanlända" for newly arrived) is used to distinguish the target of the survey from other forms of global mobility such as expatriates.

The criterion used to identify organizations as medium-sized or large was having at least 50 employees. An online survey link was sent to HR managers in 1,629 firms in industries including manufacturing, information and communications technology, professional services, mining, energy, water and wastewater services, construction and finance. During the period from June to August 2019, 330 fully or partially completed questionnaires were received. After excluding questionnaires with more than $10 \%$ of responses missing, responses from 249 businesses were included in the analysis. The response rate was around $15 \%$. The comparison of early and late respondents showed no statistically significant differences regarding the study constructs. 


\section{Measures}

Table 1 presents the main constructs and the items and the scale used to measure each construct. The typology of CDS, organizational culture and selection/promotion criteria are the main constructs. Demographic characteristics including firm size, level of human capital
International skilled migrants

\begin{tabular}{ccc}
\hline & $\#$ & \\
Construct & Items & Content \\
\hline
\end{tabular}

Cultural diversity strategy $\quad$ My organization...

Homogeneity $\quad 1 \quad \ldots$ appreciates similarity. We hold a strong belief that organizational goals are best reached under conditions of shared values and a common goal. In that way, we can operate under conditions of strong unity. Therefore, we attract and retain staff who share the dominant culture and values of our organization

Blind

$1 \quad \ldots$ is not consciously active in becoming more diverse. We aim at hiring the best candidate for each position. If we happen to attract more people from a different cultural background, this is because they are the best candidates and fit the job requirements best

Fairness $\quad 1 \quad \ldots$ wants to become more diverse because all humans are equal and deserve an equal chance. By hiring people of various cultural backgrounds, we strive to provide such equal chances. In order to promote their advancement in the organization, we consider it important to take extra measures to support them

Learning $\quad 1 \quad \ldots$ wants to become more diverse because we think that there is a lot to learn from different cultures. As a result, we can perform our work better and define new goals. Collaboration improves, we develop ourselves and work outcomes are better because of the different perspectives that are available to us

Access $\quad 1 \quad \ldots$ wants to become more diverse because with different cultural groups represented on our staff, and we will be better able to serve our clients/customers who come from various backgrounds. In our current composition, we are less effective in addressing the needs of certain groups of customers

Good worker $\quad 1 \quad \ldots$ employs migrant as they are generally good diligent workers, willing to work in less desired jobs with a shortage of labor. We view these jobs often as entry jobs with lower skill levels

Scale: 1-4 (1: does not apply at all, 2: tends not to apply, 3: tends to apply and 4: fully applies)

\section{Organizational culture}

Clan 4

Ad-hocracy $\quad 4$

Market 4

Hierarchy
Personal atmosphere, mentor-style leadership, loyalty and tradition, cohesion and morale (Cronbach's alpha $(\alpha)=0.76$ )

Entrepreneurial dynamism, risk-taking, leadership, innovation and growth $(\alpha=0.73)$

$4 \quad$ Production oriented, goal-oriented leadership, task accomplishment and competitiveness $(\alpha=0.76)$

4 Formalization, coordinator-style leadership, presence of rules and policies and stability $(\alpha=0.82)$

Scale: 0-100 (a total of 100 points are distributed among the four statements describing each of the organizational culture types)

Selection and career development criteria Human capital 2 Cultural capital 2 Social capital 1 Competency 2 Language

1

Formal education and work experiences

Fitting to the work culture and adapting Swedish values

The informal network

Performance and communication capability

Swedish language proficiency

Scale: 1-5 (1: not important, 2: of little importance, 3: of average importance, 4: important and 5: absolutely essential)

Table 1.

Study constructs and measures 
JGM

9,2

296 needed and the firm's degree of internationalization are also examined to identify the patterns in their relationships with the CDS.

CDSs include six types. Podsiadlowski et al. (2013) developed vignettes for measuring five types. The sixth type, the good worker strategy, was developed by the authors. Each vignette, presented in Table 1, briefly explains the cultural diversity situation in the organization also the goal and logic of diversity. The CDS is measured using a four-point Likert scale. A scale with an even number of levels was used to avoid uncertain or neutral responses and to reveal valence answers to questions about the sensitive issue of diversity (Kulas and Stachowski, 2009).

Organizational culture was measured using four items from the Organization Culture Assessment Instrument, developed by Cameron and Quinn (2011). HR managers and diversity officers were asked to allocate 100 points between four statements describing each of the organizational culture types, based on the similarity of the statement to their organization. For example, the first item was about the overall description of the organization and the four statements were the following: (1) personal atmosphere related to clan culture: "the organization is a very special place. It is like an extended family. People seem to share a lot of themselves;" (2) entrepreneurial dynamism related to ad hocracy culture: "the organization is a very dynamic and entrepreneurial place. People are willing to stick their necks out and take risks;" (3) production oriented related to market culture: "the organization is very production oriented. A major concern is with getting the job done. People are very competitive and achievement oriented" and (4) formalization related to hierarchy culture: "the organization is a very formalized and structured place. Bureaucratic procedures generally govern what people do."

The main selection and development criteria were measured by asking respondents to determine the importance of eight criteria for selection and development using a five-point Likert scale.

Regarding organizational demographics, the size of the organization was proxied by the number of employees, using the scale from "1: 50-99 employees" to " 6 : more than 2,000 employees." The degree of internationalization of the firm was measured by the three items: percentage of export of total sales, number of foreign subsidiaries/branches and number of foreign countries as customers (Sullivan, 1994). The dominant language used in the firm's daily business communications was coded as "1: Swedish" or "2: English." No firm reported using a language other than English or Swedish.

\section{Data analysis}

Businesses often adopt a portfolio of strategies rather than a unique strategy (Tharenou and Kulik, 2020). Our empirical data support this statement. The average number of strategies reported high per firm is 2.7 . In average, each business either fully applies or tends to apply more than two different types of diversity strategies. This indicates that organizations adopt a portfolio of strategies to guide their diversity practices. Therefore, cluster analysis is used to capture the presence of coherent clusters of organizations with similar CDSs. Cluster analysis can reveal patterns of association among the organizational culture, the choice of CDS and the selection/development criteria.

Exploratory classification based on cultural diversity approaches is used (the inductive method of clustering) (Ketchen and Shook, 1996). This enables us to develop a detailed description of the configuration of diversity strategies without overspecifying the model (Ketchen and Shook, 1996). A two-step cluster analysis technique is used. This technique is an exploratory tool designed to reveal natural groupings (or clusters) within a data set and automatically determines the number of clusters (Crum et al., 2020; Ordanini et al., 2004). Through clustering, each organization is assigned to one portfolio. 
Then, the mean values of clusters are compared to the answers to respond RQ1 and RQ2. Analysis of variance or equivalent nonparametric Kruskal-Wallis (1952) test is used to assess the differences among clusters on variables such as culture and selection criteria. The clustering and mean analysis enables us to determine the configuration of culture, cultural diversity and selection in the organizations. In case of statistically significant results, a follow-up test of least significant difference (LSD) or nonparametric Mann-Whitney U (Wilcoxon rank) was performed to compare each pair of clusters and identify clusters that differ from the others.
International skilled migrants

297

\section{Results}

The means, standard deviations and correlations of the main study constructs are presented in Table 2. The sum of the means of the four types of organizational culture is 100 because the measure asked each respondent to allocate 100 points between the four types. The dominant type of culture among the sample of Swedish organizations is clan culture, followed by market culture $\left(M_{\text {clan }}-M_{\text {Market }}=10.93, t=6.11\right.$ and $\left.p<0.001^{* * * *}\right)$.

Competency, language, cultural capital and human capital are the most important criteria for selection and development. The differences between their levels of importance are not statistically significant. Social capital is the least important criterion ( $M_{\text {HumanCapital }}-$ $M_{\text {SocialCapital }}=1.27$, Mann-Whitney $Z=12.4$ and $p<0.001^{* * * *}$ ).

The most common CDSs practiced in Sweden are blind, learning and fairness. The mean differences among these strategies are not statistically significant. The homogeneity strategy is the next most common strategy $\left(M_{\text {Fairness }}-M_{\text {Homogeneity }}=0.34, t=4.49\right.$ and $\left.p<0.001\right)$. The access and good worker diversity strategies have means less than 2.5 and are the least common diversity strategies $\left(M_{\text {Homogeneity }}-M_{\text {Access }}=0.25, t=2.76\right.$ and $p<0.001$; $M_{\text {Access }}-M_{\text {GoodWorker }}=0.75, t=8.56$ and $\left.p<0.001\right)$.

To systematically identify the similar bundles of diversity strategies among organizations, a two-step cluster analysis was used. The cluster analysis resulted in the identification of five clusters. As shown in Table 3, cluster 1 is the largest cluster and comprises $26 \%$ of the organizations. Cluster 5 is the smallest cluster and comprises $14 \%$ of the organizations. The ratio of the largest to smallest cluster is 1.86 , which is less than the maximum acceptable level of 3 .

\begin{tabular}{llcc}
\hline Construct & Typology & Mean & SD \\
\hline Cultural diversity strategy (1-4) & Blind & 3.18 & 0.89 \\
& Learning & 3.08 & 0.76 \\
& Fairness & 3.04 & 0.71 \\
& Homogeneity & 2.70 & 0.98 \\
& Access & 2.45 & 0.89 \\
& Good worker & 1.70 & 0.84 \\
Organizational culture (0-100) & Clan & 37.3 & 16.5 \\
& Market & 26.3 & 14.2 \\
& Ad-hocracy & 20.3 & 11.4 \\
Selection and career development criteria (1-5) & Hierarchy & 16.1 & 11.9 \\
& Competency & 4.29 & 0.20 \\
& Language proficiency & 3.96 & 1.01 \\
& Cultural capital & 3.68 & 0.29 \\
& Human capital & 3.66 & 0.31 \\
& Social capital & 2.39 & 0.91
\end{tabular}

Table 2.

Means and standard deviations of main constructs 
$\underset{9,2}{\text { JGM }}$

298

Table 3.

Clusters and their configuration

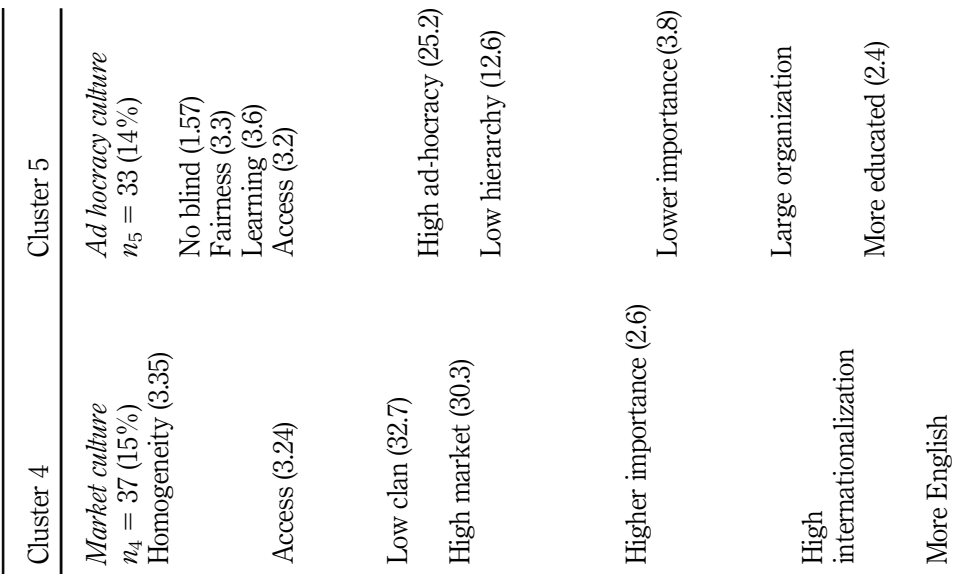

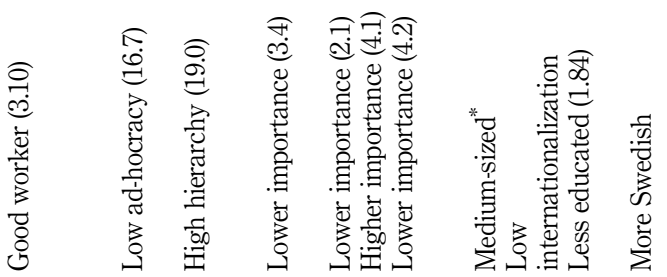

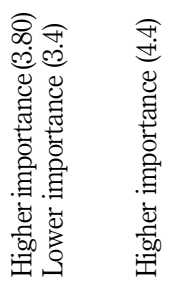

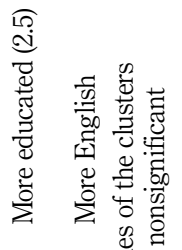

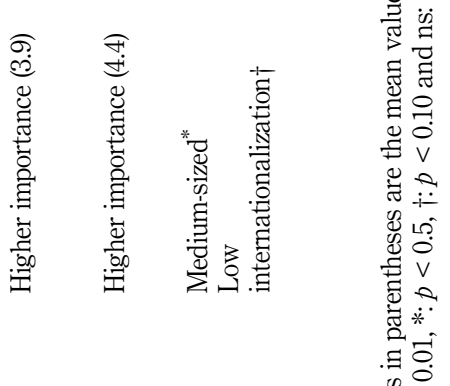

妾 V

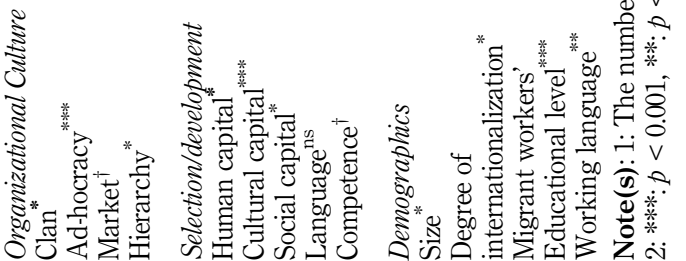


After classifying the organizations into clusters based on their CDS, the five clusters are compared based on their organizational culture, selection and career development criteria and demographic characteristics. Analysis of variance (ANOVA) or equal nonparametric Kruskal-Wallis test was run to determine whether the means of clusters' organizational culture, selection criteria and organizational demographics are different. The cluster membership was used as the grouping variable.

To evaluate the reliability of the clustering solution, the sample was split and the two-halves clustered separately. Also, the clustering was repeated using a different method (K-means cluster analysis, setting the number of clusters to five). The results of two methods of clustering were consistent, which indicates reliability. To test the validity of clusters, the means of the clustering variables (i.e. CDS) and nonclustering variables (i.e. culture, selection and development criteria) are compared; statistically significant differences across clusters show that the cluster solution is valid and reflects the underlying structure of the data.

The results regarding research questions 1 and 2 are summarized in Table 3 . The columns denote the five clusters and show the configuration of CDS, organizational culture, selection/ development criteria and firm demographics within each cluster. Numbers in parentheses denote the cluster's average level of the variable and determine whether each cluster has high or low levels of the tested variables in relation to other clusters.

\section{Discussion}

As shown in Table 1, the highest average score for organizational culture is related to clan culture. This type of culture emphasizes collective actions such as teamwork, consensus and participation. Clan culture is characterized by conformity and interdependence. One may find this surprising because the national culture of Sweden is known to be an individualistic culture (Heu et al., 2018). However, Holmberg and Akerblom (2006) have indicated that, unlike the private sphere, in Swedish style at the societal level, including in the workplace, democratic decision-making, dialogue and consensus-building and pursuit of unity are common. This justifies the high score of clan culture in our Swedish sample.

Regarding CDSs, the most frequent strategies are blind, learning and fairness. However, the rationale behind each of these popular strategies might be different. Organizational responses to diversity are conceptualized as a consequence of institutional pressures. Yet, the diversity management responses can vary significantly and are derived by different external forces and internal motivations (Ortlieb and Sieben, 2013; Thomas and Ely, 1996). The blind strategy is a defensive strategy and assures that the organization follows regulations (institutional pressures through legislatives such as the Equal Opportunities Act by the International Labour Organization, the Sweden Discrimination Act), the learning strategy is a long-term strategy to maximize competitiveness and the fairness strategy is a proactive strategy explained mainly by moral impetus, which is mainly internal and for instance might stem from executives/founders ethical considerations.

In order to make sense of the results and provide a comprehensive summary, clusters are positioned on the organizational culture typology. As shown in Figure 2 and noted by a reviewer of this paper, all clusters (with the exception of cluster 2) neatly align with organizational cultures. This indicates that organizational cultures are the determinants that lead to CDS and HR approaches. In the following, each cluster is explained, and the consequences of the culture for ISMs' employment and career outcomes are discussed.

The clan culture cluster is the largest cluster. Clan culture organizations utilize homogeneity and blind strategies jointly. Their selection and promotion decisions are made mainly based on person-organization fit as the cultural capital is the most important criteria. The control in the clan cluster is based on adhering to shared norms, and values and employees are expected to be a regular member and behave properly, consistent with agreed upon behaviors (Ouchi, 1980). 
JGM

9,2

\section{0}

\section{Figure 2.}

Five clusters of businesses and configuration of organizational culture and cultural diversity strategy

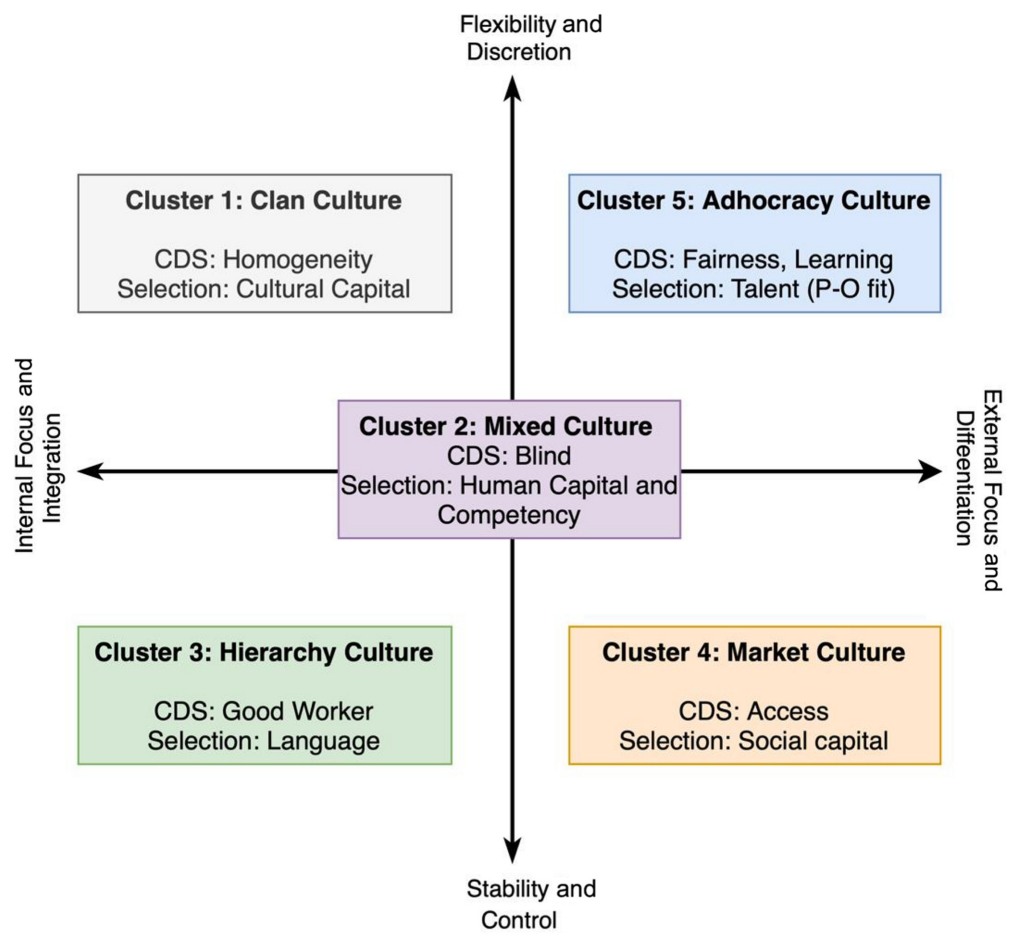

Note(s): The location of the clusters denotes only the cluster's quadrant and does not reflect the location of the center of the cluster, the distance between the clusters, the size or the cluster's distribution

In order to be a regular employee, IMSs as newcomers, need time to develop their language capabilities but more importantly familiarize themselves with the professional accepted behavior in the new setting. These behaviors are either in the form of codified code of conduct or in the form of unwritten rules governing daily business communication and behavior (Hervas-Oliver et al., 2013). Mastering the latter is challenging, particularly for a newly arrived IMS. Furthermore, clan culture emphasizes consensus, cohesion and embracing organizational values, which mirror societal values. Because ISMs are habituated to a different value system and work culture, they are considered a misfit to the organizational culture, and they are therefore seen as less employable. Thus, it seems logical to assume that the configuration of the culture and homogeneity diversity strategy in clan cluster reduces the chances of recruitment and career success for not-assimilated migrant workers. Clan organizations use the blind strategy for diversity management and use competence as the selection criteria. This means that the organization has no plan or agenda for proactively increasing diversity. As they show less propensity to fairness or access strategies, they are most likely to use a blind strategy in job categories where there is a local skill shortage, where they use competence as the selection criteria (i.e. assessing the communication capability of the candidate to work in the established cohesive team and their ability to comply with the organization's norms and behavioral standards). The majority of firms in the clan cluster are medium-sized local businesses that provide goods and services mainly to Swedish customers, which justify their search for similar minded employees. Our finding is compatible with the previous research that associates a 
smaller size and a local clientele with a homophilous hiring tendency (Almeida et al., 2012; Murase et al., 2019).

The second cluster is relatively large and comprises $25 \%$ of organizations. As shown in Figure 2, the position of cluster 2 suggests that it includes all types of organizational culture, and there is no dominant culture in this group. Cluster 2 does not utilize either the fairness or homogeneity strategy. This means that organizations in this cluster neither proactively look for native applicants nor do they proactively attract migrant applicants. They are relatively blind organizations $\left(M_{\mathrm{Blind}}\right.$ cluster1 $=M_{\mathrm{Blind,cluster2}}$ at $p=0.08$ and $M_{\mathrm{Blind}}$, cluster2 $>M_{\mathrm{Blind}}$, cluster5 at $p<0.001)$. In selection and promotion decisions, individual performance, education and experience (i.e. competence and human capital) play the main role. It appears that person-job fit is the main paradigm for HR decisions in this cluster. These organizations are more likely to have English as their working language and often employ highly educated migrant workers. This mixed culture cluster often assesses ISMs as highly employable because ISMs often possess a high level of human capital and competency and a higher likelihood of proficiency in English language than a local language (i.e. Swedish).

The hierarchy culture cluster encompasses $20 \%$ of the sample. The hierarchy culture emphasizes control and efficiency (i.e. cost reduction). Therefore, they use the good worker strategy and are likely to employ migrant workers with a lower level of education because they are considered to be productive, work longer and with more flexibility and more inclined than native workers to accept lower wages due to their vulnerable position in the labor market. This cluster comprises mostly medium-sized businesses and businesses likely to have jobs that are less complex and can be closely monitored and so require lower levels of skills. Therefore, no apparent criteria for selection appears and the person's willingness to take a job that is most likely a less attractive entry-level job are sufficient (Janssens and Zanoni, 2014; MacKenzie and Forde, 2009). An ISM in such an organization is more likely to be employed in an overqualified position.

The market cluster includes $15 \%$ of organizations in the sample. This type of organizations utilizes a wide range of CDSs. Their market culture is customer oriented; therefore, they might deploy an access strategy, which means employing migrant as cultural brokers in jobs for which a dual cultural background is an asset, such as serving customers with a similar foreign culture or language (Liversage, 2009; Ortlieb and Sieben, 2013). The organizations' higher degree of internationalization means they are frequently dealing with international customers, and their employment positions require familiarity with different cultures and languages. The market culture does not rely on loyalty, cooperation or a sense of belonging to a social system; however, there is a lean normative structure to govern behaviors (Kerr and Slocum, 2005). The competitive environment organizations and their aggressive approach for fulfilling customers' needs might lead them to be less inclined to employ newly arrived migrants with no proof of competence. Therefore, they might either provide training and mentorship to migrant workers to acculturate them (in organizations with a high level of fairness strategy) or employ candidates based on their achievements or supported by referrals from credible professionals (in organizations with a homogeneity strategy, placing importance in social capital and informal referrals). To be employed in a market culture organization, an IMS need to develop their professional network as social capital is a main selection criterion. ISMs should also consider that informal referrals rather than formally announced job advertisement is the main recruitment channel for this cluster.

Ad hocracy culture cluster is the fifth and smallest cluster, incorporating $15 \%$ of Swedish organizations. This culture is associated with creativity, change and entrepreneurship, emphasizing personal development and mentorship. This cluster considers IMS as a source of competitive advantage because they bring new perspectives that foster innovation and organizational learning. They are mostly large organizations; therefore, it can be assumed that they can formally assign sufficient resources to diversity or corporate social 
JGM

9,2

responsibility initiatives to employ IMSs and assist them in the integration phase (Berthou and Buch, 2018). Ad hocracy culture is not blind and proactively promotes cultural diversity, attracts talents, including individuals with a migrant background, and offer special training and mentorship to actualize their talent. This is in congruence with the fact that no specific selection criteria appear for this cluster, and they formally train and develop an IMS with high potential (i.e. talents). Ad hocracy culture targets to attract IMSs for key organizational positions based on their potential human capital contribution rather than other capital considerations (Crowley-Henry and Al Ariss, 2018).

\section{Conclusion}

This empirical inquiry attempts to better understand the complexity of diversity in organizations and offers several potential contributions to the diversity and global mobility literature. First, we study a newly spotted group of migrants and extend previous global mobility research to include ISMs. ISMs are a group different than expatriates. Despite progress in addressing emergent mobility issues, until recently, research had largely overlooked this important group that growing in number (Hajro et al., 2019; Tharenou and Kulik, 2020). While expatriate adjustment and acculturation is a main theme of research for expatriates, ISM research should consider both adjustment to the new societal and work culture and at the same time career and occupational identity reestablishment. The ISM should reconstruct their career by seeking a job and finding employment. Second, the current study has provided preliminary evidence for the fit between culture and HRM strategy and processes and migrant career outcomes. As asserted in the strategic HRM literature, culture is key to organizational performance, and more work is needed to integrated constructs from the culture to HRM (Palthe and Kossek, 2003). This paper focused on the link between organizational culture and the diversity strategy and selection/development. We suggest that organizational culture is relevant to the strategic decisions of the firm regarding diversity and HR processes (e.g. selection and development) and provided empirical evidence on this relationship. The typology of "organizational culture $\rightarrow$ diversity strategy $\rightarrow$ HR" fit is shown in Figure 2. Typologies are key building blocks of management research and are an important way of organizing complex cause-effect relationships. Here, we developed a novel perspective on cultural diversity, based on how elements of an organization's culture, diversity and HR are connected. An initial attempt is made to theorize the effects of organizational culture as antecedent of cultural diversity and HR processes.

We explore CDSs in Swedish organizations and identify the most frequently used strategies (i.e. blind, learning and fairness). However, in practice, it appears organizations use a portfolio of strategies. The existence of a portfolio might be due to the presence of competing rationales for diversity for different job categories or in different geographical locations or because of the lack of an organization-wide strategic plan for diversity. As one reviewer notices, this might be due to limitation in the measurement of the strategies by one item and in 1-4 scale. Development and validation of a summative measure for cultural diversity should be pursued by future research.

Configurations of organizational culture and demographics as antecedent of CDS and HR processes as the consequence of CDS are identified. Further research, using qualitative methods and longitudinal methods, is required to elaborate the revealed relationships in this research. For instance, investigating the history of evolution of CDS portfolio and the rationale behind the events is needed to provide us with better understanding. It should be noted that the ISM also evolves. As years of residency increases, the language proficiency, cultural capital and social capital of ISMs increase. Future studies should focus on career movement and progress of the migrants through the time and the effects on their individuallevel variables such as career satisfaction and performance. 
We propose that the organizational culture, the ISM's modes of acculturation, should be studied. Berry (1980) identified four modes of acculturation of a migrant based on his/her degree of (1) high/low maintaining one's heritage culture and identity and (2) high/low adoption of the cultural identity of the host group. The acculturation modes are labeled as integration, assimilation, separation and marginalization. It appears clan, hierarchy, market and ad hocracy cultures are, respectively, associated with the ISM's assimilation, marginalization, separation and integration. ISMs that are assimilated, dismissed their original identity and mastered cultural identity of the new country are a match to clan organizations that seek similarity by accentuating cultural capital. ISMs that are integrated and have kept their original identity while adopting cultural identity of the new country fit ad hocracy organizations. These organizations consider ISMs' talents and sources of learning and innovation. Marginalized ISMs are a match for the hierarchy organizations that the good worker CDS leads to offering jobs with no clear cultural/occupational identity. Separated ISM fit in the market culture as access CDS let them keep and utilize their country-of-origin cultural identity without requiring them to adopt cultural identity of the new country. Further research is needed to study the relationship between individual acculturation inside different organizational cultures.

The findings provide practical implications for managers, ISMs and labor market intermediaries. Migrant workers should know that organizations' demographics, culture, strategy and types of processes make some organizations more receptive than others to migrant workers. Some type of organizations should be prioritized in job-seeking activities (e.g. those with market or ad hocracy cultures). Some indicators of attractive organizations for ISMs include having a diverse clientele, an international value chain, an export orientation, an official diversity program or signaling the significance of cultural diversity in their job adverts and proactively seek to reach a diverse group of candidates, for example by participating in migrant integration initiatives. Some organizations, mainly with hierarchy culture, provide "survival jobs" that can be utilized in order to learn the host country's language and work culture, and the local social network (e.g. organization with hierarchy culture) and some organizations prefer assimilated and accultured migrants (e.g. organizations with clan culture).

Organizations should train their managers regarding the range of possible perspectives on cultural diversity and the probable effects of each perspective on lives and careers of migrants. Awareness and knowing the consequences helps the manager to make informed decisions regarding employment and development of migrants and provide better organizational support when needed. For smaller organizations with less resources available, labor market intermediaries might interfere. State-owned employment offices, unions, civil society organizations and nongovernmental organizations can provide educational seminars for smaller businesses and should attempt to formalize the discourse on cultural diversity in the labor market, in similar fashion to discourse on gender diversity. Substantial evidence support the positive effect of regulation and official discourses on one in the participation of the minority group in organizations (e.g. the case of gender diversity) (Klettner et al., 2016).

Our findings provide some clues to explain why previous research has reported lower levels of career attainment and career mobility for ISMs. A newly arrived migrant worker has fewer opportunities in the new labor market than other workers because some organizations give substantial weight to cultural and social capital in their hiring decisions, and migrants typically have lower levels of cultural and social capital at the beginning of their time in the country. An ISM might reestablish his/her career capital by finding a survival job. By mastering the host country's culture and language, they will improve their level of employability and might gain employment in an organization within cluster 2 or even clan culture organization. A number of ISMs might be able to get a job that matches their
International skilled migrants 
JGM

9,2

304

qualifications after arrival in a ad hocracy culture organization that proactively seeks diversity and promotes workplace inclusion. Also, a migrant background is an asset for cultural-broker types of jobs in a market-oriented organization. However, the effects of each cultural diversity approach on the employment and career outcomes for migrant workers require further investigation to provide concrete evidence regarding the effects of different configurations on the inclusion of migrants in the workplace. For instance, consider Cluster 2: because the cluster is clearly against the homogeneity strategy, it appears that skilled ISMs with proper job qualifications have a similar probability of employment and development to a native worker. However, this cluster also has no inclination to the fairness strategy and is less likely to assist migrant workers in their job-seeking efforts. Previous empirical studies show that organizations that use the blind diversity strategy might help in maintaining the current unequal system and have negative implications for minorities' perceptions and outcomes and for inclusion of migrants in organizational contexts (Knowles et al., 2009; Plaut et al., 2018). Therefore, the effects of the blind strategy's neutral approach to nationality and ethnicity need to be studied further, for example, by speculating that the effects may differ depending on the interaction with the organizational culture.

Swedish migration policy is mainly based on human rights in contrast to countries such as Canada and Australia that have a point-based system to attract highly educated and skilled migrants in a systematic manner. According to the Swedish Migration Agency, in 2018, 55\% of issued residence permits were related to family reunification and asylum-seeking while $31 \%$ of residencies were based on employment. As work is not the main criterion for the decision to migration and employability is less emphasized in granting the residency permit, migrants in Sweden need support to find a decent employment. In this regard, an organization should be encouraged and engaged in tackling the challenge of migration inclusion. The inclusion in the labor market is a sustainable path to be integrated to the host society. Organizations can and should shape their approach toward immigrant workers and therefore adopt a more risk averse approach to employ IMSs. Moving toward proactive diversity approaches such as learning and fairness and setting cultural diversity goals as part of corporate social responsibility agenda can be helpful.

From an organizational perspective, the effect of cultural diversity on performance should be studied further. The body of literature on ethnic minorities and immigrants in organizations is inconclusive regarding the effect of diversity. Null, negative and positive effects of diversity on performance are reported (Shore et al., 2009). A follow-up qualitative study, examining cluster practices in more detail can ensure the external validity of the cluster-based conceptualization proposed here. Furthermore, it can theorize the moderating and mediating variables that regulate the cultural diversity-performance relationship. Overall, the findings imply that diversity can enhance firm performance and career outcomes of the migrants as long as the appropriate fit among culture, strategy and process and also the migrant acculturation is established.

\section{References}

Al Ariss, A. and Syed, J. (2011), "Capital mobilization of skilled migrants: a relational perspective", British Journal of Management, Vol. 22 No. 2, pp. 286-304.

Almeida, S., Fernando, M. and Sheridan, A. (2012), "Revealing the screening: organisational factors influencing the recruitment of immigrant professionals", The International Journal of Human Resource Management, Vol. 23 No. 9, pp. 1950-1965.

Andresen, M., Bergdolt, F., Margenfeld, J. and Dickmann, M. (2014), "Addressing international mobility confusion-developing definitions and differentiations for self-initiated and assigned expatriates as well as migrants", The International Journal of Human Resource Management, Vol. 25 No. 16, pp. 2295-2318. 
Balaji, M., Jiang, Y., Singh, G. and Jha, S. (2020), "Letting go or getting back: how organization culture shapes frontline employee response to customer incivility", Journal of Business Research, Vol. 111, pp. 1-11.

Barak, M.E.M. (2016), Managing Diversity: Toward a Globally Inclusive Workplace, Sage Publications, Thousand Oaks, California.

Berry, J.W. (1980), “Acculturation as varieties of adaptation”, Acculturation: Theory, Models and Some New Findings, Vol. 9, p. 25.

Berthou, S.K.G. and Buch, A. (2018), "Perfect match? The practice ecology of a labor market initiative

International skilled migrants for refugees", Nordic Journal of Working Life Studies, Vol. 8, pp. 27-46.

Bourdieu, P. (2008), "15 the forms of capital", Readings in Economic Sociology, Vol. 4 No. 280, pp. 280-291.

Cameron, K. and Quinn, R. (1999), Diagnosing and Changing Organizational Culture, Reading, Addison-Wesley, MA.

Cameron, K.S. and Quinn, R.E. (2011), Diagnosing and Changing Organizational Culture: Based on the Competing Values Framework, Jossey-Bass, San Francisco, California.

Cerdin, J.L., Dine, M.A. and Brewster, C. (2014), "Qualified immigrants' success: exploring the motivation to migrate and to integrate", Journal of International Business Studies, Vol. 45 No. 2, pp. 151-168.

Cooke, F.L., Zhang, J. and Wang, J. (2013), "Chinese professional immigrants in Australia: a gendered pattern in (re) building their careers", The International Journal of Human Resource Management, Vol. 24 No. 13, pp. 2628-2645.

Crowley-Henry, M. and Al Ariss, A. (2018), "Talent management of skilled migrants: propositions and an agenda for future research", The International Journal of Human Resource Management, Vol. 29 No. 13, pp. 2054-2079.

Crum, M., Nelson, T., de Borst, J. and Byrnes, P. (2020), "The use of cluster analysis in entrepreneurship research: review of past research and future directions", Journal of Small Business Management, pp. 1-40, doi: 10.1080/00472778.2020.1748475.

DeFillippi, R.J. and Arthur, M.B. (1994), "The boundaryless career: a competency-based perspective”, Journal of Organizational Behavior, Vol. 15 No. 4, pp. 307-324.

Dobbin, F., Kim, S. and Kalev, A. (2011), "You can't always get what you need: organizational determinants of diversity programs”, American Sociological Review, Vol. 76 No. 3, pp. 386-411.

Dwyer, S., Richard, O.C. and Chadwick, K. (2003), "Gender diversity in management and firm performance: the influence of growth orientation and organizational culture", Journal of Business Research, Vol. 56 No. 12, pp. 1009-1019.

Emilsson, H. and Irastorza, N. (2019), "30 percent lower income: a follow-up of the Swedish 2008 Labour migration reform", MIM Working Paper Series, Vol. 19, p. 1.

Erel, U. (2010), "Migrating cultural capital: Bourdieu in migration studies", Sociology, Vol. 44 No. 4, pp. $642-660$.

Farashah, A.D. and Blomquist, T. (2020), "Exploring employer attitude towards migrant workers: evidence from managers across Europe", Evidence-based HRM: A Global Forum for Empirical Scholarship, Vol. 8 No. 1, pp. 18-37.

Fernando, W.D.A. and Cohen, L. (2016), "Exploring career advantages of highly skilled migrants: a study of Indian academics in the UK", The International Journal of Human Resource Management, Vol. 27 No. 12, pp. 1277-1298.

Findler, L., Wind, L.H. and Barak, M.E.M. (2007), "The challenge of workforce management in a global society: modeling the relationship between diversity, inclusion, organizational culture, and employee well-being, job satisfaction and organizational commitment", Administration in Social Work, Vol. 31 No. 3, pp. 63-94. 
JGM

9,2

Guerrero, L. and Hakak, L.T. (2019), 'Congruence of economic mobility beliefs and immigrants' self-esteem”, Journal of Global Mobility, Vol. 7 No. 2, pp. 181-193.

Guerrero, L. and Rothstein, M.G. (2012), "Antecedents of underemployment: job search of skilled immigrants in Canada”, Applied Psychology, Vol. 61 No. 2, pp. 323-346.

Guillaume, Y.R., Dawson, J.F., Otaye-Ebede, L., Woods, S.A. and West, M.A. (2017), "Harnessing demographic differences in organizations: what moderates the effects of workplace diversity?", Journal of Organizational Behavior, Vol. 38 No. 2, pp. 276-303.

Hajro, A., Gibson, C.B. and Pudelko, M. (2017), "Knowledge exchange processes in multicultural teams: linking organizational diversity climates to teams' effectiveness", Academy of Management Journal, Vol. 60 No. 1, pp. 345-372.

Hajro, A., Stahl, G.K., Clegg, C.C. and Lazarova, M.B. (2019), "Acculturation, coping, and integration success of international skilled migrants: an integrative review and multilevel framework", Human Resource Management Journal, Vol. 29 No. 3, pp. 328-352.

Hakak, L.T., Holzinger, I. and Zikic, J. (2010), "Barriers and paths to success: Latin American MBAs' views of employment in Canada", Journal of Managerial Psychology, Vol. 25 No. 2, pp. 159-176.

Hartnell, C.A., Ou, A.Y., Kinicki, A.J., Choi, D. and Karam, E.P. (2019), "A meta-analytic test of organizational culture's association with elements of an organization's system and its relative predictive validity on organizational outcomes", Journal of Applied Psychology, Vol. 104 No. 6, p. 832.

Hervas-Oliver, J.-L., Rosholm, M., Røed, M. and Schøne, P. (2013), “Are new work practices and new technologies biased against immigrant workers?", International Journal of Manpower, Vol. 34 No. 8, pp. 1016-1022, doi: 10.1108/IJM-08-2013-0190.

Heu, L., van Zomeren, M. and Hansen, N. (2018), "Lonely alone or lonely together? A culturalpsychological examination of individualism-collectivism and loneliness in five European countries", Personality and Social Psychology Bulletin, Vol. 45 No. 5, pp. 780-793.

Holmberg, I. and Åkerblom, S. (2006), "Modelling leadership_-implicit leadership theories in Sweden", Scandinavian Journal of Management, Vol. 22 No. 4, pp. 307-329.

Holvino, E. and Kamp, A. (2009), "Diversity management: are we moving in the right direction? Reflections from both sides of the North Atlantic", Scandinavian Journal of Management, Vol. 25 No. 4, pp. 395-403.

Janssens, M. and Zanoni, P. (2014), "Alternative diversity management: organizational practices fostering ethnic equality at work", Scandinavian Journal of Management, Vol. 30 No. 3, pp. 317-331.

Janssens, M. and Zanoni, P. (2005), "Many diversities for many services: theorizing diversity (management) in service companies", Human Relations, Vol. 58 No. 3, pp. 311-340.

Joy, S., Game, A.M. and Toshniwal, I.G. (2018), “Applying Bourdieu's capital-field-habitus framework to migrant careers: taking stock and adding a transnational perspective", The International Journal of Human Resource Management, Vol. 31 No. 20, pp. 2541-2564.

Kerr, J. and Slocum, J.W. (2005), "Managing corporate culture through reward systems", Academy of Management Executive, Vol. 19 No. 4, pp. 130-137.

Ketchen, D.J. and Shook, C.L. (1996), "The application of cluster analysis in strategic management research: an analysis and critique", Strategic Management Journal, Vol. 17 No. 6, pp. 441-458.

Klettner, A., Clarke, T. and Boersma, M. (2016), "Strategic and regulatory approaches to increasing women in leadership: multilevel targets and mandatory quotas as levers for cultural change", Journal of Business Ethics, Vol. 133 No. 3, pp. 395-419.

Knowles, E.D., Lowery, B.S., Hogan, C.M. and Chow, R.M. (2009), "On the malleability of ideology: motivated construals of color blindness", Journal of Personality and Social Psychology, Vol. 96 No. 4, p. 857. 
Kruskal, W.H. and Wallis, W.A. (1952), "Use of ranks in one-criterion variance analysis", Journal of the American Statistical Association, Vol. 47 No. 260, pp. 583-621.

Kulas, J.T. and Stachowski, A.A. (2009), "Middle category endorsement in odd-numbered Likert response scales: associated item characteristics, cognitive demands, and preferred meanings", Journal of Research in Personality.

Leschke, J. and Weiss, S. (2020), "With a little help from my friends: social-network job search and overqualification among recent intra-EU migrants moving from east to west", Work, Employment and Society, Vol. 34 No. 5, pp. 769-788.

Liversage, A. (2009), "Vital conjunctures, shifting horizons: high-skilled female immigrants looking for work", Work, Employment and Society, Vol. 23 No. 1, pp. 120-141.

Lu, Y., Samaratunge, R. and Härtel, C.E. (2016), "Predictors of acculturation attitudes among professional Chinese immigrants in the Australian workplace", Journal of Management and Organization, Vol. 22 No. 1, p. 49.

Luik, M.-A., Emilsson, H. and Bevelander, P. (2018), "The male immigrant-native employment gap in Sweden: migrant admission categories and human capital", Journal of Population Research, Vol. 35 No. 4, pp. 363-398.

MacKenzie, R. and Forde, C. (2009), "The rhetoric of thegood worker'versus the realities of employers' use and the experiences of migrant workers", Work, Employment and Society, Vol. 23 No. 1, pp. 142-159.

McGuire, D. and Lozada, M. (2017), “I'll do it step by step': care, cover and quiet campaigning”, Work, Employment and Society, Vol. 31 No. 1, pp. 175-184.

Montoya, R.M. and Horton, R.S. (2013), "A meta-analytic investigation of the processes underlying the similarity-attraction effect", Journal of Social and Personal Relationships, Vol. 30 No. 1, pp. 64-94.

Murase, Y., Jo, H.H., Török, J., Kertész, J. and Kaski, K. (2019), "Structural transition in social networks: the role of homophily", Scientific Reports, Vol. 9 No. 1, pp. 1-8.

Murray, P.A. and Ali, F. (2017), "Agency and coping strategies for ethnic and gendered minorities at work", The International Journal of Human Resource Management, Vol. 28 No. 8, pp. 1236-1260.

Noon, M. (2012), "Simply the best? The case for using 'threshold selection'in hiring decisions", Human Resource Management Journal, Vol. 22 No. 1, pp. 76-88.

Nordin, M. and Rooth, D. (2007), "Income gap between natives and second generation immigrants in Sweden: is skill the explanation?”, IZA Discussion Paper No. 2759.

OECD (2019), International Migration Outlook 2019, OECD Publishing, Paris.

Ordanini, A., Micelli, S. and Di Maria, E. (2004), "Failure and success of b-to-b exchange business models:: a contingent analysis of their performance”, European Management Journal, Vol. 22 No. 3, pp. 281-289.

Ortlieb, R. and Sieben, B. (2013), "Diversity strategies and business logic: why do companies employ ethnic minorities?", Group and Organization Management, Vol. 38 No. 4, pp. 480-511.

Ouchi, W.G. (1980), "Markets, bureaucracies, and clans", Administrative Science Quarterly, pp. 129-141.

Palthe, J. and Kossek, E.E. (2003), "Subcultures and employment modes: translating HR strategy into practice”, Journal of Organizational Change Management, Vol. 16 No. 3, pp. 287-308.

Plaut, V.C., Thomas, K.M., Hurd, K. and Romano, C.A. (2018), "Do color blindness and multiculturalism remedy or foster discrimination and racism?”, Science, Vol. 27 No. 3, pp. 200-206.

Podsiadlowski, A., Gröschke, D., Kogler, M., Springer, C. and Van Der Zee, K. (2013), "Managing a culturally diverse workforce: diversity perspectives in organizations", International Journal of Intercultural Relations, Vol. 37 No. 2, pp. 159-175.

Ressia, S., Strachan, G. and Bailey, J. (2017), "Going up or going down? Occupational mobility of skilled migrants in Australia”, Asia Pacific Journal of Human Resources, Vol. 55 No. 1, pp. 64-85.

Rodriguez, J.K., Mearns, L. and Harvey, W.S. (2012), "Labour market experiences of skilled British migrants in Vancouver", Employee Relations, Vol. 34 No. 6, pp. 658-669.
International skilled migrants 
JGM

9,2

Sarpong, D. and Maclean, M. (2019), "Moving on up? Exploring the career journeys of skilled migrants in the professions", The International Journal of Human Resource Management, pp. 1-29, doi: 10.1080/09585192.2019.1629987.

Schneider, B., González-Romá, V., Ostroff, C. and West, M.A. (2017), "Organizational climate and culture: reflections on the history of the constructs in the journal of applied psychology", Journal of Applied Psychology, Vol. 102 No. 3, p. 468.

Selmer, J. (1999), "Career issues and international adjustment of business expatriates", Career Development International, Vol. 4 No. 2, pp. 77-87.

Shirmohammadi, M., Beigi, M. and Stewart, J. (2019), "Understanding skilled migrants' employment in the host country: a multidisciplinary review and a conceptual model”, The International Journal of Human Resource Management, Vol. 30 No. 1, pp. 96-121.

Shore, L.M., Chung-Herrera, B.G., Dean, M.A., Ehrhart, K.H., Jung, D.I., Randel, A.E. and Singh, G. (2009), "Diversity in organizations: where are we now and where are we going?", Human Resource Management Review, Vol. 19 No. 2, pp. 117-133.

Shore, L.M., Cleveland, J.N. and Sanchez, D. (2018), "Inclusive workplaces: a review and model", Human Resource Management Review, Vol. 28 No. 2, pp. 176-189.

Statistics Sweden (2019), Labour Force Surveys (LFS) Annual averages 2019, available at: https:// www.scb.se/en/finding-statistics/statistics-by-subject-area/labour-market/labour-force-surveys/ labour-force-surveys-lfs/pong/statistical-news/labour-force-surveys-lfs-labour-force-surveys-lfsannual-averages-2019/.

Sullivan, D. (1994), "Measuring the degree of internationalization of a firm", Journal of International Business Studies, Vol. 25 No. 2, pp. 325-342.

Supangco, V. and Mayrhofer, W. (2014), "Determinants of work role transition outcomes of Filipinos in Singapore", Journal of Global Mobility, Vol. 2 No. 3, pp. 317-341.

Tharenou, P. and Kulik, C.T. (2020), "Skilled migrants employed in developed, mature economies: from newcomers to organizational insiders", Journal of Management, Vol. 46 No. 6, pp. 1156-1181.

Thomas, D.A. and Ely, R. (1996), "Making differences matter: a new paradigm for managing diversity", Harvard Business Review, Vol. 74 No. 5, pp. 70-90.

Thompson, P., Newsome, K. and Commander, J. (2013), “Good when they want to be': migrant workers in the supermarket supply chain", Human Resource Management Journal, Vol. 23 No. 2, pp. 129-143.

Wassermann, M., Fujishiro, K. and Hoppe, A. (2017), "The effect of perceived overqualification on job satisfaction and career satisfaction among immigrants: does host national identity matter?", International Journal of Intercultural Relations, Vol. 61, pp. 77-87.

Wittek, B.H. (2019), "Where are we today in understanding the role of the firm as a driver of international flows of highly skilled migrants? Reviewing the status of the literature on direct and indirect host country meso-level influences", The International Journal of Human Resource Management, pp. 1-34, doi: 10.1080/09585192.2019.1651378.

Yang, Y. and Konrad, A.M. (2011), "Understanding diversity management practices: implications of institutional theory and resource-based theory", Group and Organization Management, Vol. 36 No. 1 , pp. 6-38.

\section{Corresponding author}

Ali Farashah can be contacted at: ali.farashah@mdh.se

For instructions on how to order reprints of this article, please visit our website:

www.emeraldgrouppublishing.com/licensing/reprints.htm

Or contact us for further details: permissions@emeraldinsight.com 